\title{
A TEORIA DO ADIMPLEMENTO SUBSTANCIAL E O PRINCÍPIO DA BOA- FÉ OBJETIVA
}

Aliciene Bueno Antocheves de Lima ${ }^{1}$

RESUMO: Este artigo trata da relativização do direito do credor de resolver o contrato por inadimplemento, a partir da aplicação da doutrina do adimplemento substancial. Mostra-se ainda a relação desta teoria com o princípio da boa-fé objetiva,e como ela é aplicada no direito brasileiro. Será também analisada a origem da teoria do substancial performance, e como ela influenciou os tribunais brasileiros no julgamento de casos de resolução de contratos, primando pela conservação da relação obrigacional sempre que possível.

PALAVRAS-CHAVE: resolução, adimplemento substancial, boa-fé.

ABSTRACT: This article deals with the relativization of the right of the creditor to decide the contract without payment, from the application of the doctrine of the substantial performance. Also will be show the relation of this theory with the principle of objective good-faith, and as it is applied in the Brazilian law. Still it will analyses the beginning of this theory and how it influenced the Brazilian tribunals in cases of contracts resolution, privileging the conservation of the obligatory relation when possible.

KEY-WORDS: resolution, substancial performance, good-faith.

\section{INTRODUÇÃO}

$\mathrm{O}$ art. $475^{2}$ do Novo Código Civil Brasileiro traz o direito do credor de resolver o contrato em caso de inadimplemento da outra parte, assegurando-lhe ainda a indenização por perdas e danos. Porém, em que medida este direito contemplado pela legislação referida é absoluto no direito contratual?

Com o advento do princípio da boa-fé objetiva e sua difusão no direito brasileiro, foi-se limitando tal direito do credor quando o inadimplemento da obrigação contratual se mostrava insignificante, a ponto de não interferir nos efeitos do contrato. Com isso, adotou-se a doutrina do adimplemento substancial, a qual já era largamente utilizada por outros ordenamentos jurídicos, principalmente na Europa, onde teve sua origem.

Logo, pode-se dizer que a teoria do adimplemento substancial, também conhecida como "substancial performance", permitiu a relativização do art. 475, ao impedir que um contrato seja resolvido quando o seu incumprimento não altera essencialmente a base contratual. A conservação da relação obrigacional neste caso

\footnotetext{
${ }^{1}$ Acadêmica do 50 Semestre do Curso de Direito da UFSM.

${ }^{2}$ Art. 475. A parte lesada pelo inadimplemento pode pedir a resolução do contrato, se não preferir exigir-lhe o cumprimento, cabendo, em qualquer dos casos, indenização por perdas e danos.
}

ISSN - 1981-3694

(C) 2007. Departamento de Direito da UFSM. Todos os direitos reservados. 
garante uma maior segurança jurídica às partes, as quais, contratando de acordo com a boa-fé objetiva esperada, desejam que o contrato seja cumprido.

Mister ressaltar que, embora já largamente adotada pela jurisprudência brasileira, a doutrina do adimplemento substancial não estava expressa no Código Civil de 1916, e também não foi positivada no Código Civil de 2002. Porém, sua aplicação ganhou uma base mais sólida com o implemento da boa-fé objetiva no art. $422^{3}$, já que ambos os institutos estão estritamente relacionados.

Visa-se portanto, com este trabalho, analisar o instituto do adimplemento substancial, como sendo uma das formas de tradução da boa-fé objetiva na prática jurídica, e ainda verificar a sua importância para o direito contratual, já que possibilita a preservação da relação negocial mesmo quando a legislação, tecnicamente, permitiria a sua resolução.

\section{TEORIA DO ADIMPLEMENTO SUBSTANCIAL: ORIGEM E DEFINIÇÃO}

O incumprimento das obrigações contratuais dá ao credor o direito de resolver o contrato ou exigir o seu cumprimento coativamente, se isto ainda for de seu interesse. Qualquer das duas hipóteses será também acompanhada de uma indenização por perdas e danos, de acordo com o estipulado no art. 475 do Novo Código Civil.

Vale-se salientar que quando se trata de inadimplemento do contrato, este pode se apresentar de três formas distintas, de acordo com Alves Jones Figueiredo (2005, p. 407), as quais seriam:

- Inadimplemento relativo: este se configura quando o cumprimento da obrigação ainda é possível, embora seja tardio.

- Inadimplemento absoluto: ocorre quando o descumprimento da obrigação contratada inviabiliza qualquer forma de manutenção posterior do contrato, restando apenas a sua resolução e indenização.

- Inadimplemento insignificante: este ocorre quando o descumprimento do contrato atinge proporções mínimas, de tal modo que não chega a afetar os efeitos esperados pelo contrato.

Quando se está diante desta terceira modalidade de inadimplemento referido acima é que surge a teoria do adimplemento substancial. Esta, por sua vez, consiste na situação 
em que o devedor não cumpre parte de sua obrigação, embora já tenha executado a maioria do contrato, porém, injusto seria para ambas as partes resolver a relação contratual, já que os efeitos pretendidos pelo contrato permanecem intactos frente ao inadimplemento insignificante. Resta, assim, para o credor, apenas a possibilidade de ressarcimento dos seus prejuízos, mesmo que secundários.

A doutrina do adimplemento substancial teve sua origem em 1779, nos tribunais ingleses, com o caso Boone versus Eyre (OMAIRI, 2005), no qual o Julgador da questão, Lord Mansfield, declarou ser o direito de resolução, naquela situação, abusivo, permitindo apenas a indenização, já que o contrato havia sido adimplido substancialmente. No Brasil, o responsável por introduzir a doutrina do substancial performance foi o jurista Clóvis do Couto e Silva, fundamentando a sua utilização em decorrência do princípio da boa-fé objetiva, embora este ainda não fosse expresso no Código Civil de 1916. A sua definição desta doutrina foi reproduzida por Jones Figueiredo Alves (2005, p.408), a qual seria "Um adimplemento tão próximo ao resultado final, que, tendo-se em vista a conduta das partes, exclui-se o direito de resolução, permitindo tão-somente o pedido de indenização e/ou de adimplemento, vez que aquela primeira pretensão viria a ferir o princípio da boa-fé."

Ainda de acordo com Alves, o primeiro tribunal brasileiro a introduzir a teoria do adimplemento substancial foi o Tribunal de Justiça do Rio Grande do Sul, sendo o jurista Clóvis do Couto e Silva o magistrado responsável pela lide. A partir de então, a resolução contratual em decorrência do inadimplemento do devedor passou a ser relativizada sempre que este não afetava os efeitos pretendidos pelo contrato. Assim, a sua preservação, baseando-se na boa-fé objetiva dos contratantes, possibilitou uma maior garantia à segurança jurídica da relação obrigacional.

Pode-se afirmar que a teoria do adimplemento substancial consiste principalmente num instrumento do próprio magistrado, ao analisar o caso concreto. Isto ocorre em decorrência desta teoria não ter sido abarcada pela legislação civil de 1916, e novamente não ser mencionada no Código Civil de 2002. Ela é aplicada divido a uma interpretação das leis e dos princípios que as regem, tornando-se indispensável para que o direito contratual siga os seus propósitos de manter a relação obrigacional.

Logo, pode-se perceber que a doutrina do substancial performance, embora não positivada, tem grande importância e aplicação no direito brasileiro. Ela é uma das

\footnotetext{
${ }^{3}$ Art. 422. Os contratantes são obrigados a guardar, assim na conclusão do contrato, como em
} 
responsáveis pela manutenção do contrato sempre que isto for possível, algo que é amplamente resguardado pela legislação brasileira desde o Código Civil de 1916.

\subsection{Aplicação na vigência do Código Civil de 1916 (aqui deve ser 1.1)}

A inserção da doutrina do adimplemento substancial no Direito brasileiro não é um fato contemporâneo. Com a vigência do Código Civil de 1916, o jurista Clóvis do Couto e Silva já a difundia pelos tribunais do país, ampliando gradativamente a sua aplicação nos casos em que o inadimplemento, por não afetar significativamente a execução do contrato e seus efeitos, revelava-se mínimo.

Sabe-se que o substancial performance e a boa-fé objetiva estão estritamente relacionados, já que o último tem como uma de suas funções a limitação de direitos subjetivos que propiciem a abusividade, e o primeiro é o exercício disso. No entanto, a legislação civil de 1916 não havia positivado este princípio, como ocorreu em 2002, com o Novo Código. Desta forma, como se fundamentava a aplicação da doutrina do adimplemento substancial, já que esta também não era uma norma?

O fato da boa-fé objetiva não estar positivada, não significa que ela não era contemplada pelo Ordenamento jurídico brasileiro. De acordo com Aguiar Júnior (1991, p.242), “[...] a regra da boa fé é uma cláusula geral, como tantas outras do nosso ordenamento."

Além disso, fundamentava-se a aplicação da doutrina do adimplemento substancial como se ela fosse "uma interpretação integradora" (ALVES, 2005, p. 408) do art. $85^{4}$ do Código civil de 1916. Ao firmar um contrato, a intenção das partes deveria ser de executá-lo, para que ele produzisse seus efeitos. Se um dos contratantes inadimplisse parte de suas obrigações, porém não afetando o suporte fáctico do contrato, desnecessário que este se resolvesse, já que se desejava, num primeiro momento, extrair da contratação a totalidade de seus efeitos.

Durante a vigência do vetuso código civil, portanto, aplicou-se a doutrina do adimplemento substancial a partir de uma interpretação da legislação em questão, utilizando ainda como reforço a boa-fé dos contratantes, ocupando esta o papel de cláusula geral, e não de um princípio positivado, como veio a ocorrer com o advento do Novo Código Civil.

\footnotetext{
sua execução, os princípios de probidade e boa-fé.

${ }^{4}$ Nas declarações de vontade se atenderá mais à sua intenção que ao sentido literal da linguagem.
} 


\subsection{Aplicação na vigência do Novo Código Civil: a boa-fé}

Durante a existência do Código Civil de 1916, a boa-fé era apenas uma regra geral do direito brasileiro, não sendo portanto algo concreto, capaz de fundamentar, exclusivamente, a teoria do adimplemento substancial. Isto, no entanto, alterou-se com a vigência da nova legislação civil, em 2002, quando a boa-fé objetiva foi abordada expressamente no seu art. 422.

A boa-fé é um dos princípios basilares para a formação e execução dos contratos. No entanto, no que consiste a boa-fé objetiva? Esta seria um conjunto de atribuições que ambas as partes contratantes devem possuir no momento da contratação. Estas atribuições, todavia, são analisadas de acordo com o homem médio da sociedade brasileira, e não de acordo com as qualidades subjetivas das partes em questão.

Segundo Arnaldo Rizzardo (2004, p.32), “A segurança das relações jurídicas depende, em grande parte, da probidade e da boa-fé, isto é, da lealdade, da confiança recíproca, da justiça, da equivalência das prestações e contraprestações, da coerência e clarividência dos direitos e deveres."

Há duas funções principais da boa-fé objetiva no direito contratual. Ela pode criar deveres secundários de conduta ou ainda impor limites ao exercício de direitos. Em relação à doutrina do adimplemento substancial, importa a segunda função.

Como já foi mencionado, o art. 475 do Código Civil permite a resolução do contrato devido ao inadimplemento da outra parte, ou ainda exigir o cumprimento forçado da obrigação, acrescido ambos de indenização pelo prejuízo. Com o princípio da boa-fé objetiva, limita-se este direito do credor quando se está diante de casos em que isto corresponderia a uma abusividade, como por exemplo na situação de um adimplemento substancial, no qual a maior parte do contrato já foi cumprida, sendo o seu incumprimento insignificante comparado ao todo.

Portanto, pode-se afirmar que o direito do credor de resolver o contrato face ao inadimplemento não é absoluto, já que se deve respeitar o princípio da boa-fé objetiva na formação e execução do mesmo. Sempre que este direito for utilizado, configurando uma abusividade do credor, ele será inibido pelo princípio da boa-fé, garantindo a segurança jurídica da relação obrigacional.

Conforme Ruy Rosado Aguiar Jr. (1991, p. 248), “[...] o princípio da boa-fé impõe aos contratantes o dever de agir de modo a assegurar à contraparte a plena realização das legítimas expectativas derivadas do contrato". Desta forma, aquele que 
adimpliu substancialmente a sua obrigação tem, evidentemente, a intenção de cumprir a totalidade do contrato. Permitindo a resolução contratual nesses casos, estar-se-ia negando a necessidade da existência da boa-fé, abalando assim a segurança jurídica do negócio.

Com o Código Civil de 2002 houve a concretização do princípio da boa-fé objetiva no ordenamento jurídico brasileiro. Com isso, facilitou-se a aplicação da teoria do adimplemento substancial, relativizando o disposto no art. 475 e garantindo a preservação da relação obrigacional, tão estimada pela legislação atual.

Nota-se que, embora esta doutrina tenha sido aplicada tanto durante a vigência do vetuso Código Civil quanto no de 2002, as suas fundamentações alteraram de uma legislação para a outra, devido à positivação da boa-fé objetiva, que deixou de ser uma mera cláusula geral e se tornou um princípio expresso no ordenamento jurídico brasileiro.

\section{O "SUBSTANCIAL PERFORMANCE" NA JURISPRUDÊNCIA BRASILEIRA}

Como já foi mencionado, a doutrina do adimplemento substancial não foi uma inovação do Código Civil de 2002. Ela já era muito utilizada na vigência do vetuso Código, e continuou sendo aplicada na atual legislação, mesmo não possuindo uma norma correspondente em ambas codificações.

Por não configurar uma lei específica, o substancial performance se consolidou no Brasil através das decisões jurisprudenciais, que aplicam a teoria sempre que há o inadimplemento de um contrato que já foi cumprido quase que integralmente, não permitindo a sua resolução.

O Tribunal de Justiça do Rio Grande do Sul foi o pioneiro na aplicação da teoria do adimplemento substancial. Através de uma pesquisa jurisprudencial, encontra-se em seu acervo ${ }^{5}$ acórdãos datados desde 1988.

EMENTA: CONTRATO. RESOLUCAO. ADIMPLEMENTO SUBSTANCIAL. O COMPRADOR QUE PAGOU TODAS AS PRESTACOES DE CONTRATO DE LONGA DURACAO, MENOS A ULTIMA, CUMPRIU SUBSTANCIALMENTE O CONTRATO, NAO PODENDO SER DEMANDADO POR RESOLUCAO. ACAO DE RESCISAO JULGADA IMPROCEDENTE E PROCEDENTE A CONSIGNATORIA. APELO

\footnotetext{
${ }^{5}$ Pesquisa efetuada através do site www.tj.rs.gov.br
} 
PROVIDO EM PARTE, APENAS RELATIVAMENTE AOS HONORARIOS. (Apelação Cível N 588012666, Quinta Câmara Cível, Tribunal de Justiça do RS, Relator: Ruy Rosado de Aguiar Júnior, Julgado em 12/04/1988)

Embora a Legislação Civil de 1916 admitisse a utilização da doutrina do inadimplemento insatisfatório, há um número relativamente baixo de acórdão que trazem esta questão. Isto foi modificado com o Código Civil de 2002, que aumentou significamente a sua aplicação, em decorrência da positivação do princípio da boa-fé objetiva.

APELAÇÃO CÍVEL. ALIENAÇÃO FIDUCIÁRIA. PROCESSUAL CIVIL. AÇÃO DE BUSCA E APREENSÃO. CONTRATO DE ABERTURA DE CRÉDITO FIXO COM GARANTIA REAL FINAME AUTOMÁTICO. FINANCIAMENTO COM PACTO ADJETO DE ALIENAÇÃO FIDUCIÁRIA. INADIMPLEMENTO RELATIVO ÀS DUAS ÚLTIMAS PARCELAS DO FINANCIAMENTO. CASO CONCRETO. NOTIFICAÇÃO IRREGULAR. APLICAÇÃO DA TEORIA DO ADIMPLEMENTO SUBSTANCIAL DO CONTRATO. CABIMENTO. O ADIMPLEMENTO SUBSTANCIAL DO CONTRATO NÃO AUTORIZA AO CREDOR A PROPOSITURA DA AÇÃO PARA A EXTINÇÃO DO PACTO, CONSIDERANDO-SE A BOA-FÉ OBJETIVA E AS CIRCUNSTÂNCIAS DO CASO EM TELA. SENTENÇA MANTIDA, POR FUNDAMENTOS DIVERSOS. DESPROVERAM A APELAÇÃO. (Apelação Cível No 70016192940, Décima Terceira Câmara Cível, Tribunal de Justiça do RS, Relator: Angela Terezinha de Oliveira Brito, Julgado em 14/12/2006)

Pode-se perceber que na ementa acima se trata do caso de desprovimento da ação de busca e apreensão devido ao adimplemento substancial do contrato, fundamentado na boa-fé objetiva, que veio expressa na nova legislação civil, em seu art 422. Desta forma, é possível perceber que embora a boa-fé já fosse tida como uma cláusula geral no antigo código, a sua positivação em 2002 deu uma maior segurança para pleitear o cabimento do adimplemento substancial.

A alegação do adimplemento substancial do contrato também é muito comum quando envolve o contrato de seguro. Esta situação já foi inclusive matéria do Superior Tribunal de Justiça, o qual já admite a aplicação da doutrina do substancial performance desde a década de 90 .

SEGURO. INADIMPLEMENTO DA SEGURADA. FALTA DE PAGAMENTO DA ULTIMA PRESTAÇÃO. ADIMPLEMENTO SUBSTANCIAL. RESOLUÇÃO. A COMPANHIA SEGURADORA NÃO PODE DAR POR EXTINTO O CONTRATO DE SEGURO, POR FALTA DE PAGAMENTO DA ULTIMA PRESTAÇÃO DO PREMIO, POR TRES RAZÕES: A) SEMPRE RECEBEU AS PRESTAÇÕES COM ATRASO, O QUE ESTAVA, ALIAS, PREVISTO NO CONTRATO, SENDO INADMISSIVEL QUE APENAS REJEITE A PRESTAÇÃO QUANDO OCORRA O SINISTRO; B) A SEGURADORA CUMPRIU SUBSTANCIALMENTE COM A SUA OBRIGAÇÃO, NÃO SENDO A SUA FALTA SUFICIENTE PARA 
EXTINGUIR O CONTRATO; C) A RESOLUÇÃO DO CONTRATO DEVE SER REQUERIDA EM JUIZO, QUANDO SERÁ POSSIVEL AVALIAR A IMPORTANCIA DO INADIMPLEMENTO, SUFICIENTE PARA A EXTINÇÃO DO NEGOCIO. RECURSO CONHECIDO E PROVIDO. (REsp 76362 / MT ; RECURSO ESPECIAL 1995/0050635-1, T4 - QUARTA TURMA, Superior Tribunal de Justiça, Relator, julgado em 11/12/1995)

Através desta análise jurisprudencial, nota-se que, mesmo não sendo positivada, a teoria do adimplemento substancial já está consolidada no Ordenamento Jurídico brasileiro, sendo reconhecida tanto pelos Tribunais de Justiça quanto pelo próprio Superior Tribunal de Justiça. Logo, pode-se afirmar que o inadimplemento insatisfatório das obrigações contratuais não enseja a resolução do contrato, primando sempre pela manutenção da relação contratual quando for possível.

\section{CONSIDERAÇÕES FINAIS}

O inadimplemento de parte da obrigação contratual que possibilita ao credor resolver o contrato não é um direito absoluto. Em decorrência do princípio da boa-fé objetiva, o qual veio expresso no Novo Código Civil (art. 422), sempre que o inadimplemento for insatisfatório, não afetando significativamente os efeitos do contrato, aplicar-se-á a doutrina do adimplemento substancial, impossibilitando a resolução e permitindo apenas a indenização pelos prejuízos.

O Ordenamento Jurídico brasileiro prima pela manutenção da relação obrigacional sempre que possível, garantindo uma maior segurança às partes no momento de contratar. Desta forma, a teoria do substancial performance é um dos grandes responsáveis por essa garantia, sendo de suma importância para o Direito Contratual brasileiro.

Por não constituir uma lei expressa na legislação civil, esta doutrina se transformou em um instrumento do magistrado brasileiro, que o utiliza para garantir a aplicação do princípio da boa-fé objetiva, além de propiciar a conservação da relação contratual, tão estimada pelas partes envolvidas.

Através da garantia de que o contrato irá ser preservado sempre que houver condições para isso, possibilitando que seus efeitos sejam externados, acaba-se por estimular pessoas a realizarem negócios jurídicos entre si, sem medo de ter suas expectativas frustradas. A formação e execução de contratos são de extrema importância 
para a economia brasileira, assim como de qualquer outro país, e por isso deve apresentar ferramentas que viabilizem a sua manutenção até o fim de seus efeitos.

O adimplemento substancial é uma das ferramentas mencionadas acima, e sempre refletirá em uma limitação do direito do credor, evitando que haja uma abusividade por parte do mesmo. Esta doutrina é um reflexo do princípio da boa-fé objetiva, além de ser responsável por colocar em prática um dos maiores fundamentos do direito contratual, que seria a conservação da relação contratual para que o contrato surta seus efeitos.

Portanto, pode-se afirmar que o substancial performance é a prova da relativização do direito do credor estipulado no art. 475 do Código Civil. Embora não esteja presente no Ordenamento Jurídico brasileiro como uma lei expressa, a jurisprudência se encarregou de consolidar esta teoria, podendo ela servir como um instrumento de defesa para a parte devedora sempre que esta tenha cumprido grande parte de suas obrigações e não queira ver sua pretensão frustrada sem uma real necessidade.

\section{REFERÊNCIAS BIBLIOGRÁFICAS}

AGUIAR JR., Ruy Rosado. Extinção dos Contratos por incumprimento do devedor (resolução). 1.ed. Rio de Janeiro: Aide, 1991.

BORGES, Thiago. Boa-fé nos contratos: entre a fonte e a solução do caso concreto. UNIFACS, Revista Jurídica. Edição fevereiro de 2006. Disponível em: <http://www.unifacs.br/revistajuridica/edicao_fevereiro2006/docente/doc_01.doc>. Acesso em 19 jan. 2007.

BRASIL. Código Civil. 2. ed. São Paulo: Revista dos Tribunais, 1999.

BRASIL. Código Civil. 11. ed. São Paulo: Saraiva, 2005.

BRASIL. Tribunal de Justiça do Rio Grande do Sul. Apelação Cível no ${ }^{\circ 88012666 . ~} 5^{\text {a }}$ Câmara Cível. Relator Desembargador Ruy Rosado de Aguiar Júnior. Julgado em 12/04/1988. Dispinível em: <http://www.tj.rs.gov.br/site_php/jprud2/ementa.php>. Acesso em 10 fev. 2007.

BRASIL. Tribunal de Justiça do Rio Grande do Sul. Apelação Cível no 70016192940. $13^{\text {a }}$ Câmara Cível. Relatora Desembargadora Angela Terezinha de Oliveira Brito. Julagado em 12/12/2006. Disponível em: <http://www.tj.rs.gov.br/site_php/jprud2/ementa.php>. Acesso em 10 fev. 2007. 
BRASIL. Superio Tribunal de Justiça. Recurso Especial no $76362.4^{\text {a }}$ turma. Relator Desembargador Ruy Rosado Aguiar Jr. Julgado em 11/12/1995. Disponível em: $<$ http://www.stj.gov.br/SCON/jurisprudencia/doc.jsp?processo=76362\&\&b=ACOR\&p $=$ true $\& \mathrm{t}=\& \mathrm{l}=10 \& \mathrm{i}=1>$. Acesso em: $10 \mathrm{fev} .2007$.

DELGADO, Mário Luiz; ALVES, Jones Figueiredo (coord). Novo código civil: questões controvertidas no direito das obrigações e dos contratos. São Paulo: Método, 2005.

NETTO, Felipe Peixoto Braga. A responsabilidade civil e a hermenêutica contemporânea> uma nova teoria contratual? Disponível em: <http://www.prmg.mpf.gov.br/producao/artigos/Dr\%20Felipe/A\%20responsabilidade\% 20civil\%20e\%20a\%20hermeneutica\%20contemporanea.pdf>. Acesso em 19 jan. 2007.

OMAIRI, Elissane Leila. A doutrina do adimplemento substancia e sua recepção pelo direito brasileiro. In: DireitoNet, 2005. Disponível em: < http://www.direitonet.com.br/artigos/x/20/64/2064/>. Acesso em: 20 jan. 2007.

RIZZARDO, Arnaldo. Contratos: Lei ${ }^{\circ}$ 10.406, de 10.01.2002. 3.ed. Rio de Janeiro: Forense, 2004.

SILVA, Rafael Peteffi da. Teoria do adimplemento e modalidades de inadimplemento, atualizado pelo novo Código Civil. Disponível em: <http://www.advocaciapasold.com.br/publicacoes/teoriadoadimplemento.doc $>$. Acesso em 21 jan. 2007.

USTÁRroZ, Daniel. As origens da boa fé objetiva no Novo Código Civil. Disponível em <http://www.mt.trf1.gov.br/judice/jud12/origens_boa_fe.htm>. Acesso em: 20 jan. 2007. 